\title{
Sixty-sixth Refresher Course in Experimental Physics
}

10-25 December 2014

at School of Physics, Shri Mata Vaishno Devi University, Katra, J \& K

Sponsored by

Indian Academy of Sciences, Bangalore, Indian National Science Academy, New Delhi

The National Academy of Sciences, India, Allahabad

This sixty-sixth Course will be held at School of Physics, Shri Mata Vaishno Devi University, Katra, from 10-25 December 2014. Participants in this course will gain hands on experience with about twenty one out of forty experiments, including some advanced experiments at Post-MSc Level, with a low cost kit developed for the Indian Academy of Sciences, and manufactured by Ajay Sensors and Instruments in Bangalore. These experiments are in (a) mechanics (b) heat (c) electricity: both DC and AC (d) magnetism (e) optics (f) relaxation (g) phase- sensitive detection technique (h) non-linear dynamics, and (i) phase transitions.

Refresher Courses in Experimental Physics held so far have been highly successful and the experiments have been included in about 80 institutions including universities, autonomous colleges and advanced scientific institutions involved in education. Over 1200 participants have been trained so far and more than a hundred kits have been sold.

The total number of seats in the Course will be about 25; while the Course is essentially meant for teachers in universities and colleges, a few seats will be available for students of BSc 3rd year and MSc Physics courses. UGC has approved two-week Refresher Courses of good standing for the promotion of teachers, vide notification - F31/2009 dated 30 June 2010.

Applications are invited from teachers with experience in teaching undergraduate and postgraduate courses in Engineering and Physics. Motivated students of III BSc and MSc. Physics courses with keen interest in Experimental Physics may also apply. The number of seats will be about 30. Selected participants will be provided with travel assistance (limited to three-tier AC train fare), accommodation and local hospitality during the Course in addition to course material.

Interested applicants must submit their application ONLINE by clicking on the following link: http://web-japps.ias.ac.in:8080/Refreshcourse/RCSP.jsp

A copy of the application form signed by the applicant should also be sent by speed post to the Course Coordinator. In case of teachers, the form must also be signed and stamped by the Head of the applicant's Institution stating that leave will be sanctioned if the applicant is selected for the Course. A recommendation letter from a teacher is essential for student applicants. Scanned copies of the duly signed documents sent by e-mail will also be accepted.

Applications may be sent to: Dr. Jitendra Sharma, Course Coordinator, Refresher Course in Experimental Physics, School of Physics, Shri Mata Vaishno Devi University, Katra 182320, J \& K, Email: yugal@ smvdu.ac.in

Last date for the receipt of applications: 15 September 2014.

Selected participants will be informed around: 20 September 2014. 